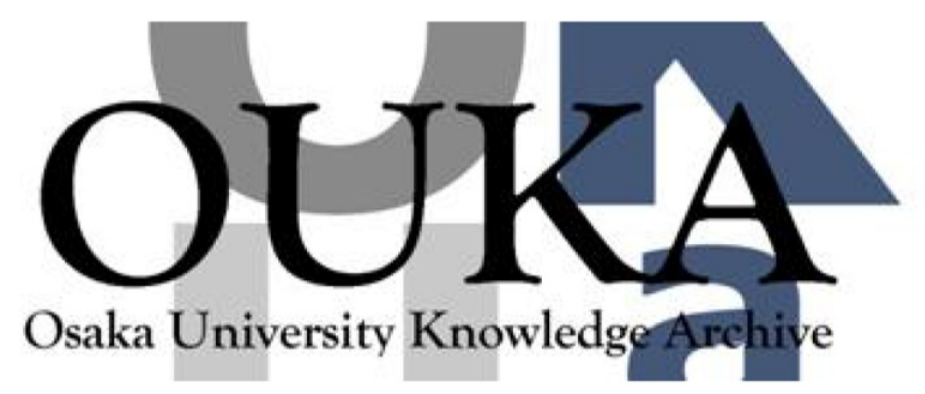

\begin{tabular}{|c|l|}
\hline Title & $\begin{array}{l}\text { Ionic Liquid Mediated Dispersion and Support of } \\
\text { Functional Molecules on Cellulose Fibers for } \\
\text { Stimuli-Responsive Chromic Paper Devices }\end{array}$ \\
\hline Author(s) & Koga, Hirotaka; Nogi, Masaya; Isogai, Akira \\
\hline Citation & $\begin{array}{l}\text { ACS Applied Materials and Interfaces. 9(46) } \\
\text { p. 40914-p.40920 }\end{array}$ \\
\hline Issue Date & $2017-11-22$ \\
\hline oaire:version & AM \\
\hline URL & https://hdl. handle. net/11094/78435 \\
\hline rights & Copyright $\odot 2017$ American Chemical Society \\
\hline Note & \\
\hline
\end{tabular}

Osaka University Knowledge Archive : OUKA

https://ir. Library. osaka-u. ac. jp/

Osaka University 


\title{
Ionic Liquid-Mediated Dispersion and Support of Functional Molecules on Cellulose Fibers for Stimuli-Responsive Chromic Paper Devices
}

\author{
Hirotaka Koga, ${ }^{, \dagger}$ Masaya Nogi, ${ }^{\dagger}$ and Akira Isogai ${ }^{\ddagger}$
}

\author{
${ }^{\dagger}$ The Institute of Scientific and Industrial Research, Osaka University, 8-1 Mihogaoka, Ibaraki, \\ Osaka 567-0047, Japan \\ Department of Biomaterials Sciences, Graduate School of Agricultural and Life Sciences, The \\ University of Tokyo, 1-1-1 Yayoi, Bunkyo-ku, Tokyo 113-8657, Japan \\ *Corresponding author: E-mail: hkoga@eco.sanken.osaka-u.ac.jp
}

\section{Keywords}

Cellulose, Paper, Supported ionic liquid, Composite, Stimuli-responsive materials 


\begin{abstract}
Functional molecules play a significant role in the development of high-performance composite materials. Functional molecules should be well dispersed (ideally dissolved) and supported within an easy-to-handle substrate, to take full advantage of their functionality and ensure easy handling. However, simultaneously achieving the dissolution and support of functional molecules remains a challenge. Herein, we propose the combination of a nonvolatile ionic liquid and an easy-to-handle cellulose paper substrate for achieving this goal. First, the photochromic molecule, i.e. diarylethene, was dissolved in the ionic liquid, 1-butyl-3-methylimidazolium bis(trifluoromethanesulfonyl)imide ([bmim] $\left.\mathrm{NTf}_{2}\right)$. Then, diarylethene/[bmim] $\mathrm{NTf}_{2}$ was supported on cellulose fibers within the paper, through hydrogen bonding between [bmim] cations of the ionic liquid and the abundant hydroxyl groups of cellulose. The as-prepared paper composites exhibited reversible, rapid, uniform, and vivid coloration and bleaching upon ultraviolet and visible light irradiation. The photochromic performance was superior to that of the paper prepared in the

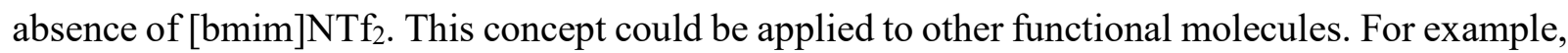
lithium perchlorate/[bmim] tetrafluoroborate supported within cellulose paper acted as a flexible electrolyte to provide a paper-based electrochromic device. These findings are expected to further the development of composite materials with high functionality and practicality.
\end{abstract}




\section{Introduction}

Functional molecules play a key role in materials development. For example, stimuli-responsive molecules, which can alter their chemical and/or physical properties in response to external stimuli, have received considerable attention as smart materials for diverse applications. ${ }^{1-3}$ Among the various stimuli-responsive molecules, chromic molecules can change their colors upon various stimuli such as light, heat, or electrons ${ }^{4}$ In particular, photochromic diarylethene and its derivatives have received much interest due to their thermal stability, rapid and reversible molecular switching, and fatigue resistance..$^{5-7}$ They have been applied in devices such as actuators, photo-optical switches, optical memory, and displays. ${ }^{8}$

Functional molecules including diarylethene are often difficult to handle, due to their molecularscale size. Thus, it can be desirable to support them on an easy-to-handle substrate. They should be well dispersed on the substrate, to suppress their aggregation and to take full advantage of their functionality. In this way, well-dispersed functional molecules, ideally being dissolved in some solvent, can be supported on substrates to obtain high-performance composite materials. However, there are challenges to achieving this. Most solvents cannot maintain the dissolution of solutes in an open system because of their evaporation.

Ionic liquids are organic salts with a melting point near or below room temperature. ${ }^{9,10}$ They are potential solvents for functional materials, because they are generally nonvolatile even under highvacuum conditions. ${ }^{11}$ Supported ionic liquids on solid substrates such as silica for catalytic applications have been reported. ${ }^{12-15}$ Among the many ionic liquids, 1-butyl-3-methylimidazolium ([bmim])-based ionic liquids can be supported on substrate materials with hydrogen-bond accepting ability, because [bmim] cations have hydrogen-bond donating ability. ${ }^{16}$ From this viewpoint, paper materials made from cellulose pulp fibers are promising substrates. Cellulose has abundant hydroxyl groups and thus excellent hydrogen-bond accepting ability, and paper is 
inexpensive, lightweight, flexible, green, and sustainable. Paper can also serve as an effective substrate for stimuli-responsive chromic molecules, since most colors display well on white paper due to its high optical reflectance. A nonvolatile ionic liquid supported on cellulose pulp fibers within paper could be an effective media to dissolve functional molecules, including photochromic diarylethenes. This combination could provide high-performance composite materials with excellent functionality and handleability.

Herein, we report stimuli-responsive chromic paper devices. They were fabricated by supporting [bmim]-based ionic liquid on cellulose pulp fibers, and using the supported ionic liquid as a layer for dissolved photochromic diarylethene (Figure 1). Supporting the ionic liquid on cellulose fibers was achieved by room-temperature solution processes. The supported ionic liquid could in turn support dissolved diarylethene on the cellulose fibers of the paper. As proof-of-concept, the asprepared paper device exhibited excellent photochromic performance with respect to color uniformity and vividness, which were significantly better than those of the paper device prepared without the ionic liquid. The nonvolatile ionic liquid ensured that the excellent photochromic performance remained largely unchanged over at least five years. The proposed strategy can be applied to various functional molecules. For example, lithium perchlorate $\left(\mathrm{LiClO}_{4}\right)$ /ionic liquid supported on paper was used as a flexible electrolyte to realize an all paper-based electrochromic device.

\section{Experimental Section}

\subsection{Materials}

Cellulose filter paper (ADVANTEC No. 5A, content of $\alpha$-cellulose: $>99$ wt. $\%$, thickness: ca. $200 \mu \mathrm{m})$ was purchased from Toyo Roshi Kaisha, Ltd., Tokyo, Japan and was cut into circularshaped pieces (ca. $90 \mathrm{mg}, 33 \mathrm{~mm}$ in diameter) before use. Cellulose nanofibers were prepared from 
softwood chips (Japanese cedar, Cryptomeria japonica), according to a previous report. ${ }^{17}$ Three types of [bmim]-based ionic liquids, i.e. [bmim] tetrafluoroborate $\left(\mathrm{BF}_{4}\right)(98.0 \%$ purity), [bmim] hexafluorophosphate $\left(\mathrm{PF}_{6}\right)\left(98.0 \%\right.$ purity), and [bmim] bis(trifluoromethanesulfonyl)imide $\left(\mathrm{NTf}_{2}\right)$ (98.0\% purity), were obtained from Tokyo Chemical Industry Co., Ltd., Tokyo, Japan. Two types of photochromic diarylethene, i.e. 1,2-bis[2-methylbenzo[b]thiophen-3-yl]-3,3,4,4,5,5-hexafluoro1-cyclopentene (>97.0\% purity) and 1,2-bis(2,4-dimethyl-5-phenyl-3-thienyl)-3,3,4,4,5,5hexafluoro-1-cyclopentene ( $>98.0 \%$ purity) were purchased from Tokyo Chemical Industry Co., Ltd., Tokyo, Japan. Tetrahydrofuran ( $99.5 \%$ purity) and isopropyl ether ( $>99.0 \%$ purity) were purchased from Wako Pure Chemical Industries, Ltd., Tokyo, Japan, and Tokyo Chemical Industry Co., Ltd., Tokyo, Japan, respectively. An aqueous dispersion of poly(3,4ethylenedioxythiophene)poly(styrenesulfonate) (PEDOT:PSS, Clevios P HC V4) was purchased from Heraeus Holding $\mathrm{GmbH}$, Hanau, Germany. $\mathrm{LiClO}_{4}$ (98.0\% purity) was obtained from Wako Pure Chemical Industries, Ltd., Tokyo, Japan. All other chemicals were of reagent grade and were used without further purification.

\subsection{Preparation of ionic liquid supported within cellulose paper substrate}

[Bmim]-based ionic liquid $(0.24 \mathrm{mmol})$ was dissolved in tetrahydrofuran $(10 \mathrm{~mL})$. Then, a piece of cellulose filter paper was immersed in the resulting solution, followed by evaporation of tetrahydrofuran at room temperature in a draft chamber. The obtained paper was thoroughly washed with isopropyl ether to remove excess ionic liquid, and was then vacuum-dried at room temperature. The ionic liquid content of the paper was calculated by weight variation.

\subsection{Preparation and evaluation of photochromic paper device}


Diarylethene $(12 \mu \mathrm{mol})$ and $[\mathrm{bmim}] \mathrm{NTf}_{2}(0.24 \mathrm{mmol})$ were dissolved in tetrahydrofuran (10 $\mathrm{mL}$ ). Then, a piece of cellulose filter paper was immersed in the resulting solution, followed by evaporation of tetrahydrofuran at room temperature in a draft chamber. The obtained paper was vacuum-dried at room temperature. The diarylethene content of the paper was measured as follows. Residual diarylethene, which was not supported within the paper, was first dissolved in diethyl ether, and was then quantified by ultraviolet-visible (UV-vis) absorption analysis using a U-670 spectrophotometer (JASCO Corp., Tokyo, Japan) (see Supporting Information, Figure S1). The amount of diarylethene supported within the paper was estimated by subtraction. To evaluate the photochromic performance, the color difference of the paper was measured using a color difference meter (CHROMA METER CR-400, Konica Minolta, Inc., Tokyo, Japan) before and after UV irradiation (UV lamp, wavelength: $312 \mathrm{~nm}$, light intensity: $110 \mu \mathrm{W} \mathrm{cm}{ }^{-2}$ ) and visible irradiation (neutral white lamp, light intensity: $100 \mu \mathrm{W} \mathrm{cm}{ }^{-2}$ ).

\subsection{Preparation and evaluation of electrochromic paper device}

$\mathrm{LiClO}_{4}$ and $[\mathrm{bmim}] \mathrm{BF}_{4}$ supported on cellulose pulp fibers within paper (denoted $\mathrm{LiClO}_{4} /[\mathrm{bmim}] \mathrm{BF} 4 @$ paper) and PEDOT:PSS-coated cellulose nanofiber paper (denoted PEDOT:PSS@nanopaper)were used as an electrolyte and a transparent electrochromic electrode, respectively. The electrochromic paper device was fabricated using two pieces of PEDOT:PSS@nanopaper and one piece of $\mathrm{LiClO}_{4} /[\mathrm{bmim}] \mathrm{BF}_{4} @$ paper. In this case, the $\mathrm{LiClO}_{4} /[\mathrm{bmim}] \mathrm{BF} 4 @$ paper was prepared as follows. [Bmim]BF $4(0.88 \mathrm{mmol})$ and $\mathrm{LiClO}_{4}(0.14$ $\mathrm{mmol})$ were dissolved in tetrahydrofuran $(10 \mathrm{~mL})$. Then, a piece of cellulose filter paper $(25 \mathrm{~mm}$ $\times 35 \mathrm{~mm}$ ) was immersed in the resulting solution, followed by evaporation of the tetrahydrofuran at room temperature in a draft chamber. The PEDOT:PSS@nanopaper was prepared similarly to our previous report. ${ }^{18}$ Briefly, an aqueous suspension of cellulose nanofibers $(0.3$ wt. $\%, 50 \mathrm{~mL})$ 
was first dewatered on a membrane filter (A010A090C, mixed cellulose ester membrane, $0.1 \mu \mathrm{m}$ pore diameter, Advantec Toyo Kaisha, Ltd., Tokyo, Japan) by suction filtration. Then, an aqueous dispersion of PEDOT:PSS with electrochromic properties $(0.008 \mathrm{wt} . \%, 15 \mathrm{~mL})$ was added and filtered in the same manner, followed by hot-pressing at $110^{\circ} \mathrm{C}$ for $7 \mathrm{~min}(1.1 \mathrm{MPa})$, and subsequent peeling from the membrane. The PEDOT:PSS@nanopaper obtained $(75 \mathrm{~mm}$ in diameter) was cut into rectangular-shaped pieces $(30 \mathrm{~mm} \times 35 \mathrm{~mm})$ before use. To fabricate the electrochromic paper device, the as-prepared $\mathrm{LiClO}_{4} /[\mathrm{bmim}] \mathrm{BF}_{4} @$ paper $(25 \mathrm{~mm} \times 35 \mathrm{~mm})$ was sandwiched between two PEDOT:PSS@nanopapers $(30 \mathrm{~mm} \times 35 \mathrm{~mm})$, using double-sided tape (NW-40, Nichiban, Tokyo, Japan). Demonstration of the electrochromic paper device was conducted using a compact DC power supply unit (PMC110-0.6A, KIKUSUI ELECTRONICS Corp., Yokohama, Japan) at a voltage of $2.0 \mathrm{~V}$ and a current of $0.06 \mathrm{~A}$.

\subsection{Analyses}

Surface observations were conducted using a field-emission scanning electron microscope (FESEM, S-4800, Hitachi High-Tech Science Corp., Tokyo, Japan) with an attached energy dispersive X-ray apparatus (EDX, EMAX ENERGY, Horiba Ltd., Kyoto, Japan). Paper samples without ionic liquid were subjected to FE-SEM analysis after sputter coating with osmium. Paper samples with ionic liquid were subjected to FE-SEM/EDX analysis without sputtering. Fourier transform infrared attenuated total reflection (FT-IR/ATR) spectra were obtained using a FT/IR-6100 instrument (JASCO Corp., Tokyo, Japan). X-ray diffraction (XRD) patterns were recorded using a Rigaku RINT 2000 diffractometer with Ni-filtered $\mathrm{Cu} K \alpha$ radiation $(\lambda=1.5418 \AA$ ) with a scanning angle $(2 \theta)$ range of $10-30^{\circ}$, at $40 \mathrm{kV}$ and $40 \mathrm{~mA}$. The crystallinity index of cellulose I was estimated from the (200) reflection $\left(2 \theta=\right.$ ca. $\left.22.6^{\circ}\right)$ according to the reported method. ${ }^{19,20}$ The tensile strength and Young's modulus of the papers were evaluated at $23{ }^{\circ} \mathrm{C}$ and $50 \%$ relative 
humidity, using a Shimadzu EZ-TEST instrument equipped with a $500 \mathrm{~N}$ load cell (pulling rate: $1.0 \mathrm{~mm} \mathrm{~min}^{-1}$, span length: $10 \mathrm{~mm}$ ). The volume resistivity was measured using a LORESTA-EP instrument (MCP-T360, Mitsubishi Chemical Analytech, Co., Ltd., Kanagawa, Japan) or a HIRESTA-UX instrument (MCP-HT800, Mitsubishi Chemical Analytech, Co., Ltd., Kanagawa, Japan).

\section{Results and discussion}

\subsection{Preparation of supported ionic liquid within cellulose fiber paper}

Supporting ionic liquids on cellulose pulp fibers within paper was achieved using roomtemperature solution processes. [Bmim]-based ionic liquids used in this study were highly viscous, leading to inconvenience for the supporting process. Therefore, tetrahydrofuran with low viscosity and high volatility was used as a solvent for the ionic liquids. First, the ionic liquid [bmim] $\mathrm{NTf}_{2}$ was dissolved in tetrahydrofuran. Cellulose filter paper ( $\alpha$-cellulose content: $>99$ wt. $\%)$ was then soaked in this solution, after which the tetrahydrofuran was allowed to evaporate within 30 min. The resulting paper was washed with isopropyl ether to remove excess [bmim] $\mathrm{NTf}_{2}$, and was then thoroughly dried under vacuum conditions. Figure 2 shows optical and FE-SEM/EDX images of the as-prepared paper. The appearance and porous structure of the paper remained almost unchanged before and after [bmim]NTf $f_{2}$ treatment (Figures $2 \mathrm{a}$ and c). However, the rough surfaces of the cellulose pulp fibers became smoother after [bmim]NTf $f_{2}$ treatment (Figures $2 b$ and d). EDX mapping images of $\mathrm{F}$, derived from $[\mathrm{bmim}] \mathrm{NTf}_{2}$, verified that $[\mathrm{bmim}] \mathrm{NTf}_{2}$ was supported on the entire surface of the cellulose pulp fibers within the paper (Figures 2e and f). FT-IR/ATR analysis also confirmed the presence of the characteristic peaks of [bmim]NTf ${ }_{2}{ }^{21,22}$ (Figure 3a), indicating the existence of [bmim] $\mathrm{NTf}_{2}$ on the cellulose pulp fibers. While ionic liquids such as $[\mathrm{bmim}] \mathrm{Cl}$ have been frequently used as an efficient solvent for cellulose, [bmim] $\mathrm{NTf}_{2}$ has almost no 
cellulose-dissolving capacitiy ${ }^{23,24}$. In the current study, there were no significant changes in the crystal structure of native cellulose (cellulose I) ${ }^{25}$ before and after [bmim]NTf 2 treatment (Figure 3b). Then, the crystallinity index of cellulose I was slightly decreased from ca. $90 \%$ to $80 \%$ after [bmim $] \mathrm{NTf}_{2}$ treatment. These results suggested that $[\mathrm{bmim}] \mathrm{NTf}_{2}$ was supported on the surfaces of cellulose fibers without large changes in the crystal structure of cellulose I. Table 1 shows selected physical and electrical properties of the as-prepared paper, denoted [bmim]NTf $\mathrm{N}_{2} @$ paper. The [bmim] $\mathrm{NTf}_{2}$ content was $2.25 \mathrm{mmol}$ g-cellulose ${ }^{-1}$ (48.5 wt.\%). The mass concentration of [bmim]NTf $f_{2}$ in the paper was ca. 497 kg m ${ }^{-3}$ The [bmim]NTf $f_{2} @$ paper exhibited improved electrical conductivity compared with the original paper. The volume resistivity of the paper decreased from $2.7 \times 10^{13}$ to $8.3 \times 10^{2} \Omega \mathrm{cm}$, indicating the entire coating of the paper with ionic conductive $[\mathrm{bmim}] \mathrm{NTf}_{2}$. The Young's modulus and tensile strength of the cellulose paper decreased from $0.34 \mathrm{GPa}$ and $5.49 \mathrm{MPa}$ to $0.21 \mathrm{GPa}$ and $2.88 \mathrm{MPa}$, respectively, after supporting [bmim $] \mathrm{NTf}_{2}$, possibly due to permeation of $[\mathrm{bmim}] \mathrm{NTf}_{2}$ into the interfaces between cellulose pulp fibers. However, the [bmim]NTf $\mathrm{N}_{2} @$ paper retained sufficient physical strength for easy handling.

The supporting of [bmim]NTf 2 onto the entire surface of the cellulose pulp fibers (Figures $2 \mathrm{c}-\mathrm{f}$ ) was attributed to the hydrogen bonding between $[\mathrm{bmim}] \mathrm{NTf}_{2}$ and cellulose (Figure 1). It has been reported that $[\mathrm{bmim}]$ cations possesses hydrogen-bond donating ability, ${ }^{16}$ and cellulose with its abundant hydroxyl groups possesses hydrogen-bond accepting ability. Furthermore, [bmim]BF 4 and $[\mathrm{bmim}] \mathrm{PF}_{6}$ were also supported on cellulose paper in the same way as $[\mathrm{bmim}] \mathrm{NTf}_{2}$ (see Supporting Information, Figures S2-3 and Table S1). Thus, it was suggested that [bmim] cations play an important role in supporting of the ionic liquid on cellulose paper due to their hydrogenbond donating ability. When these papers were immersed in polar solvents such as water, ethanol, dimethylformamide, and tetrahydrofuran, the supported ionic liquids desorbed from the cellulose paper. These results suggested that the polar surface of cellulose pulp fibers was compatible with 
the polar solvent, leading to penetration of the solvent into interfaces between the ionic liquid and cellulose pulp fibers. The supported ionic liquids largely remained adsorbed on the cellulose pulp fibers under atmospheric conditions and when immersed in non-polar solvents such as diethyl ether, isopropyl ether, toluene, and hexane.

\subsection{Photochromic paper device}

$[\mathrm{Bmim}] \mathrm{NTf}_{2}$ supported on the entire surface of cellulose pulp fibers could potentially serve as a dissolving layer for functional molecules, which could in turn provide the cellulose paper with excellent functionality (Figure 1). To demonstrate this concept, a photochromic diarylethene was used as a model functional molecule. Specifically, 1,2-bis[2-methylbenzo[b]thiophen-3-yl]3,3,4,4,5,5-hexafluoro-1-cyclopentene exhibits reversible pink-red coloration/decoloration by UV/visible light-induced switching of its molecular structure. ${ }^{26}$ Many researchers have previously reported photochromism in ionic liquids. ${ }^{27}$ As shown in Figure 4, the diarylethene/[bmim]NTf $\mathrm{N}_{2}$ mixture exhibited uniform and reversible color switching from almost colorless to pink upon UV and visible light irradiation. This suggested that diarylethene was dissolved in [bmim] $\mathrm{NTf}_{2}$, and thereby showed effective photochromism. Despite such good photochromic properties, the [bmim] $\mathrm{NTf}_{2}$ solution of diarylethene was very difficult to handle due to its viscous liquid form. Therefore, the diarylethene/[bmim]NTf $\mathrm{N}_{2}$ solution was supported on cellulose pulp fibers contained within the easy-to-handle solid cellulose paper. The procedure was as follows. Diarylethene and [bmim] $\mathrm{NTf}_{2}$ were dissolved in tetrahydrofuran, followed by soaking of the cellulose paper in the solution and then the evaporation of tetrahydrofuran. Figure 5 shows the photochromic performances of diarylethene supported within the original paper without [bmim] $\mathrm{NTf}_{2}$ (denoted as

diarylethene@paper) and in the [bmim]NTf $@$ paper (denoted as diarylethene/[bmim]NTf $\mathrm{N}_{2} @$ paper). Their photochromic performances were quantitatively 
evaluated using a color difference meter. While diarylethene exhibits photochromism even in the solid crystalline state,${ }^{8}$ diarylethene@paper exhibited poor photochromic performance. The change in color of the solid-state diarylethene within the original paper was dull, even after UV irradiation for $20 \mathrm{~s}$ (Figures 5a and c). In comparison, the diarylethene/[bmim]NTf $2 @$ paper exhibited a uniform and vivid pink color (Figures $5 b$ and $d$ ). The color difference value of the diarylethene/[bmim] $\mathrm{NTf}_{2} @$ paper was 36.48 after UV irradiation for $20 \mathrm{~s}$, which was 2.5 times higher than that of the diarylethene@paper (14.58). As shown in Figure 5g, the diarylethene/[bmim]NTf $@$ @paper exhibited second-scale rapid coloration upon UV irradiation, and its color difference value reached 50 at an UV irradiation time of $90 \mathrm{~s}$. The saturated colordifference value of the diarylethene/[bmim]NTf $@$ @paper was also much higher than that of the diarylethene@paper. It should be noted that the diarylethene content was the same in each case, and that $[\mathrm{bmim}] \mathrm{NTf}_{2}$ itself did not exhibit photochromism. Therefore, the photochromic performance of diarylethene within the cellulose paper was significantly improved by the presence of the ionic liquid [bmim]NTf $\mathrm{N}_{2}$. FE-SEM observations suggested that $[\mathrm{bmim}] \mathrm{NTf}_{2}$ assisted the homogeneous dispersion of diarylethene molecules on the cellulose pulp fibers within the paper (Figure 5f), while diarylethene aggregated in the absence of [bmim] $\mathrm{NTf}_{2}$ (Figure $5 \mathrm{e}$ ). Thus, the well-dispersed diarylethene in [bmim] $\mathrm{NTf}_{2}$, which was supported within the paper, would allow efficient UV-induced molecular switching, due to its lower steric hindrance compared with solid crystalline diarylethene. Thus, the resulting system achieved both excellent photochromic performance and practical utility.

The diarylethene/[bmim] $\mathrm{NTf}_{2} @$ paper exhibited rapid and reversible coloration and decoloration upon UV and visible light irradiation, respectively, over at least 10 cycles (Figures $5 \mathrm{~g}$ and $\mathrm{h}$ ). The excellent photochromic performance was maintained even after storing without any packaging at atmospheric conditions for at least five years, which was attributed to the nonvolatility and stability 
against moisture of [bmim]NTf 2 . As shown in Figure S4, photo-patterned coloration and various coloration such as blue and purple were also demonstrated. In summary, the diarylethene/[bmim] $\mathrm{NTf}_{2} @$ paper constitutes a new type of photo-responsive paper composite, and has various potential applications such as photo-writable and photo-erasable displays and UV sensors.

\subsection{Electrochromic paper device}

To demonstrate the versatility of our strategy, we investigated other combinations of functional molecules and [bmim]-based ionic liquids. $\mathrm{LiClO}_{4}$ has been widely used as electrolytes in various electronic applications. ${ }^{28,29}$ In this study, a $\left[\right.$ bmim] $\mathrm{BF}_{4}$ solution of $\mathrm{LiClO}_{4}$ was supported within cellulose paper in a similar manner to diarylethene, to provide an easy-to-handle paper electrolyte. An electrochromic paper device was then fabricated by sandwiching the as-prepared $\mathrm{LiClO}_{4} /[\mathrm{bmim}] \mathrm{BF} 4 @$ paper electrolyte between electrochromic conductive PEDOT:PSS-coated transparent cellulose nanofiber papers (denoted as PEDOT:PSS@nanopapers) as transparent electrochromic electrodes (Figure 6a).The PEDOT:PSS@nanopaper, which had a sheet resistance of ca. $1000 \Omega$ square $^{-1}$ and an optical transmittance of ca. $70 \%$ at a wavelength of $550 \mathrm{~nm}$, was prepared similarly to our previous report. ${ }^{18}$ As shown in Figures $6 \mathrm{~b}$ and c, the device exhibited an electrically responsive color change from light blue to dark blue at an operating voltage and current of $2.0 \mathrm{~V}$ and $0.06 \mathrm{~A}$, respectively, even when it was manually bent. It has been reported that PEDOT:PSS appears as light blue or dark blue in its oxidized or reduced state, respectively. PEDOT:PSS-based electrochromic displays can operate through electronically-induced ion transfer from electrolytes to the PEDOT:PSS electrodes. ${ }^{30-32}$ Therefore, it was suggested that the $\mathrm{LiClO}_{4} /[\mathrm{bmim}] \mathrm{BF} 4 @$ paper could serve as a flexible electrolyte. As shown in Figures 6d and e, dolphin-patterned electrochromism was demonstrated using the patterned 
PEDOT:PSS@nanopaper electrode. In summary, the $\mathrm{LiClO}_{4} /[\mathrm{bmim}] \mathrm{BF}_{4} @$ paper is a promising electrolyte material for realizing all paper-based flexible electrochromic displays.

\section{Conclusion}

We demonstrated the supporting of [bmim]-based ionic liquids within easy-to-handle cellulose paper, and used the supported ionic liquids as a dissolving layer for functional molecules such as photochromic diarylethene and $\mathrm{LiClO}_{4}$ electrolyte. The diarylethene/[bmim]NTf @paper exhibited rapid, uniform, and vivid coloration/decoloration upon UV/visible light irradiation; the photochromic performance was significantly improved by the presence of [bmim]NTf 2 . In addition, $\mathrm{LiClO}_{4} /[\mathrm{bmim}] \mathrm{BF} 4 @$ paper acted as a flexible electrolyte for a paper-based electrochromic device. Thus, this approach could provide new types of paper displays such as photochromic and electrochromic paper devices.

Importantly, the paper-supported ionic liquids allowed the homogeneous dispersion and support of functional molecules to be achieved simultaneously. This led to excellent functionality and handleability of the paper devices. This strategy can be extended to various functional molecules, and these findings will further the development of high-performance and easy-to-handle functional composites.

\section{Supporting Information}

UV-vis absorption spectrum of diethyl ether solution of diarylethene, 1,2-bis[2methylbenzo[b]thiophen-3-yl]-3,3,4,4,5,5-hexafluoro-1-cyclopentene; FE-SEM and EDX F element mapping images of cellulose paper after supporting of [bmim]BF 4 or $[\mathrm{bmim}] \mathrm{PF}_{6}$; FTIR/ATR spectra and XRD patterns of cellulose paper before and after treatment with [bmim]BF 4 
or $[\mathrm{bmim}] \mathrm{PF}_{6}$; ionic liquid content, and electrical and physical properties of the $[\mathrm{bmim}] \mathrm{BF}_{4} @$ paper and [bmim]PF6@paper; optical images of photochromic paper displays.

\section{Corresponding Author}

*E-mail address: hkoga@eco.sanken.osaka-u.ac.jp

\section{Author Contributions}

H. K. planned this study and prepared the manuscript. Experiments were carried out by H. K.

H. K., M. N. and A. I. analyzed the results and discussed the manuscript during its preparation. All authors discussed the results and implications, and commented on the manuscript at all stages.

\section{Acknowledgments}

H. K. was partially supported by Grants-in-Aid for Scientific Research (Grant No. 15H05627) from the Japan Society for the Promotion of Science, and by the Cooperative Research Program "CORE Lab" of Network Joint Research Center for Materials and Devices: Dynamic Alliance for Open Innovation Bridging Human, Environment and Materials. We thank Aidan G. Young, PhD, from Edanz Group (www.edanzediting.com/ac) for editing a draft of this manuscript.

\section{Notes}

The authors declare no competing financial interests.

\section{References}


1. Liu, F.; Urban, M. W. Recent Advances and Challenges in Designing Stimuli-Responsive Polymers. Prog. Polym. Sci., 2010, 35, 3-23.

2. Urban, M. W. Stimuli-Responsive Materials: From Molecules to Nature Mimicking Materials Design; Royal Society of Chemistry: Cambridge, 2016.

3. Wei, M.; Gao, Y.; Li, X.; Serpe, M. J. Stimuli-Responsive Polymers and Their Applications. Polym. Chem., 2017, 8, 127-143.

4. Bamfield, P. Chromic Phenomena: Technological Applications of Colour Chemistry: Edition 2; Royal Society of Chemistry: Cambridge, 2010.

5. Irie, M.; Mohri, M. Thermally Irreversible Photochromic Systems. Reversible Photocyclization of Diarylethene Derivatives. J. Org. Chem., 1988, 53, 803-808.

6. Irie, M. Diarylethenes for Memories and Switches. Chem. Rev., 2000, 100, 1685-1716.

7. Luo, Q.; Cheng, H.; Tian, H. Recent Progress on Photochromic Diarylethene Polymers. Polym. Chem., 2011, 2, 2435-2443.

8. Irie, M.; Fukaminato, T.; Matsuda, K.; Kobatake, S. Photochromism of Diarylethene Molecules and Crystals: Memories, Switches, and Actuators. Chem. Rev., 2014, 114, 1217412277.

9. Welton, T. Room-Temperature Ionic Liquids. Solvents for Synthesis and Catalysis. Chem. Rev. 1999, 99, 2071-2084.

10. Huddleston, J. G.; Visser, A. E.; Reichert, W. M.; Willauer, H. D.; Broker, G. A.; Rogers, R. D. Characterization and Comparison of Hydrophilic and Hydrophobic Room Temperature Ionic Liquids Incorporating the Imidazolium Cation. Green Chem., 2001, 3, 156-164.

11. Ngo, H. L.; LeCompte, K.; Hargens, L.; McEwen, A. B. Thermal Properties of Imidazolium Ionic Liquids. Thermochim. Acta, 2000, 357-358, 97-102. 
12. Valkenberg, M. H.; deCastro, C.; Hölderich, W. F. Immobilisation of Ionic Liquids on Solid Supports. Green Chem., 2002, 4, 88-93.

13. Mehnert, C. P.; Cook, R. A.; Dispenziere, N. C.; Afeworki, M. Supported Ionic Liquid Catalysis-A New Concept for Homogeneous Hydroformylation Catalysis. J. Am. Chem. Soc., 2002, 124, 12932-12933.

14. Fehrmann, R.; Riisager, A.; Haumann, M. Supported Ionic Liquids: Fundamentals and Applications; Wiley-VCH: Weinheim, 2014.

15. Campisciano, V.; Giacalone, F.; Gruttadauria, M. Supported Ionic Liquids: A Versatile and Useful Class of Materials. Chem. Rec., DOI: 10.1002/tcr.201700005.

16. Lungwitz, R.; Friedrich, M.; Linert, W.; Spange, S. New Aspects on the Hydrogen Bond Donor (HBD) Strength of 1-Butyl-3-methylimidazolium Room Temperature Ionic Liquids. New J. Chem., 2008, 32, 1493-1499.

17. Nogi, M.; Kim, C.; Sugahara, T.; Inui, T.; Takahashi, T.; Suganuma, K. High Thermal Stability of Optical Transparency in Cellulose Nanofiber Paper. Appl. Phys. Lett., 2013, 102, 181911.

18. Koga, H.; Nogi, M.; Komoda, N.; Nge, T. T.; Sugahara, T.; Suganuma, K. Uniformly Connected Conductive Networks on Cellulose Nanofiber Paper for Transparent Paper Electronics. NPG. Asia Mater., 2014, 6, e93.

19. Segal, L.; Creely, J. J.; Martin, A. E.; Conrad, C. M. An Empirical Method for Estimating the Degree of Crystallinity of Native Cellulose Using the X-Ray Diffractometer. Textile Res. J., 1959, 29, 786-794.

20. Alexander, L. E. X-ray Diffraction Methods in Polymer Science; Krieger, R. E. (Ed.); Huntington: New York, 1979; pp. 423-424.

21. Rajkumar, T.; Ranga Rao, G. Investigation of Hybrid Molecular Material Prepared by Ionic Liquid and Polyoxometalate Anion. J. Chem. Sci. 2008, 120, 587-594. 
22. Seki, T.; Grunwaldt, J.-D.; Baiker, A. In Situ Attenuated Total Reflection Infrared Spectroscopy of Imidazolium-Based Room-Temperature Ionic Liquids under "Supercritical" CO. J. Phys. Chem. B 2009, 113, 114-122.

23. Swatloski, R. P.; Spear, S. K.; Holbrey, J. D.; Rogers, R. D. Dissolution of Cellulose with Ionic Liquids. J. Am. Chem. Soc. 2002, 124, 4974-4975.

24. Pinkert, A.; Marsh, K. N.; Pang, S.; Staiger, M. P. Ionic Liquids and Their Interaction with Cellulose. Chem. Rev. 2009, 109, 6712-6728.

25. Atalla, R. H.; Nagel, S. C. Cellulose: Its Regeneration in the Native Lattice. Science 1974, 185, $522-523$.

26. Yun, C.; You, J.; Kim, J.; Huh, J.; Kim, E. Photochromic Fluorescence Switching from Diarylethenes and Its Applications. J. Photochem. Photobiol. C:Photochem. Rev. 2009, 10, $111-129$.

27. Pina, F.; Branco, L. C. Photochromism in Ionic Liquids. Theory and Applications, Ionic Liquids: Theory, Properties, New Approaches, Kokorin, A. (Ed.); InTech: Rijeka, 2011.

28. Deng M.-J.; Chen, K.-W.; Che, Y.-C.; Wang, I-J.; Lin, C.-M.; Chen, J.-M.; Lu, K.-T.; Liao, Y.-F.; Ishii, H. Cheap, High-Performance, and Wearable Mn Oxide Supercapacitors with Urea-LiClO 4 Based Gel Electrolytes. ACS Appl. Mater. Interfaces, 2017, 9, 479-486.

29. Bao, L.; Zou, X.; Luo, X.; Pu, Y.; Wang, J.; Lei, J. Real-Time Tracking the $\mathrm{Li}^{+}$-Ion Transition Behavior and Dynamics in Solid Poly(vinyl alcohol)/LiClO 4 Electrolytes. Sci. Rep. 2017, 7 , 45921.

30. Heuer, H. W.; Wehrmann, R.; Kirchmeyer, S. Electrochromic Window Based on Conducting Poly(3,4-ethylenedioxythiophene)-Poly(styrene sulfonate). Adv. Funct. Mater. 2002, 12, 8994. 
31. Andersson, P.; Nilsson, D.; Svensson, P.-O.; Chen, M.; Malmström, A.; Remonen, T.; Kugler, T.; Berggren, M.; Active Matrix Displays Based on All-Organic Electrochemical Smart Pixels Printed on Paper. Adv. Mater. 2002, 14, 1460-1464.

32. Santos, G. H.; Gavim, A. A.; Silva, R. F.; Rodrigues, P. C.; Kamikawachi, R. C.; de Deus, J. F.; Macedo, A. G. Roll-to-Roll Processed PEDOT:PSS Thin Flms: Application in Fexible Electrochromic Devices. J. Mater. Sci.: Mater. Electron. 2016, 27, 11072-11079. 


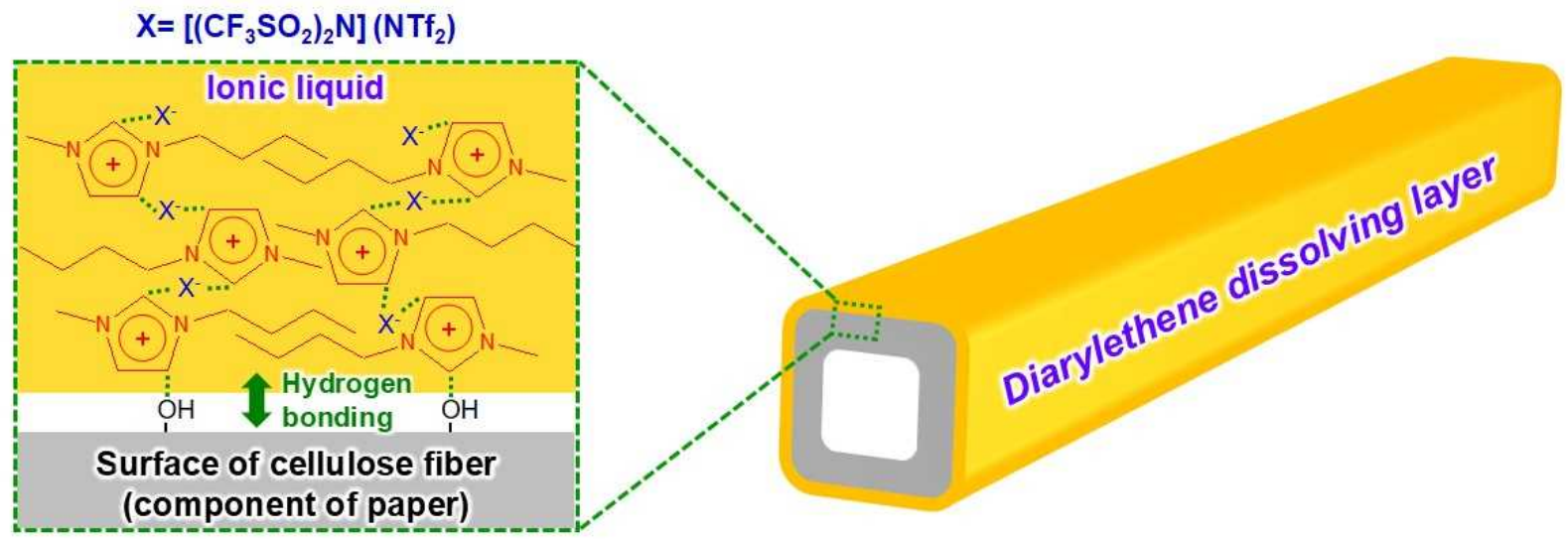

Figure 1. Schematic illustration of the supported ionic liquid [bmim] $\mathrm{NTf}_{2}$ as a dissolving layer for photochromic diarylethene on cellulose pulp fibers. 

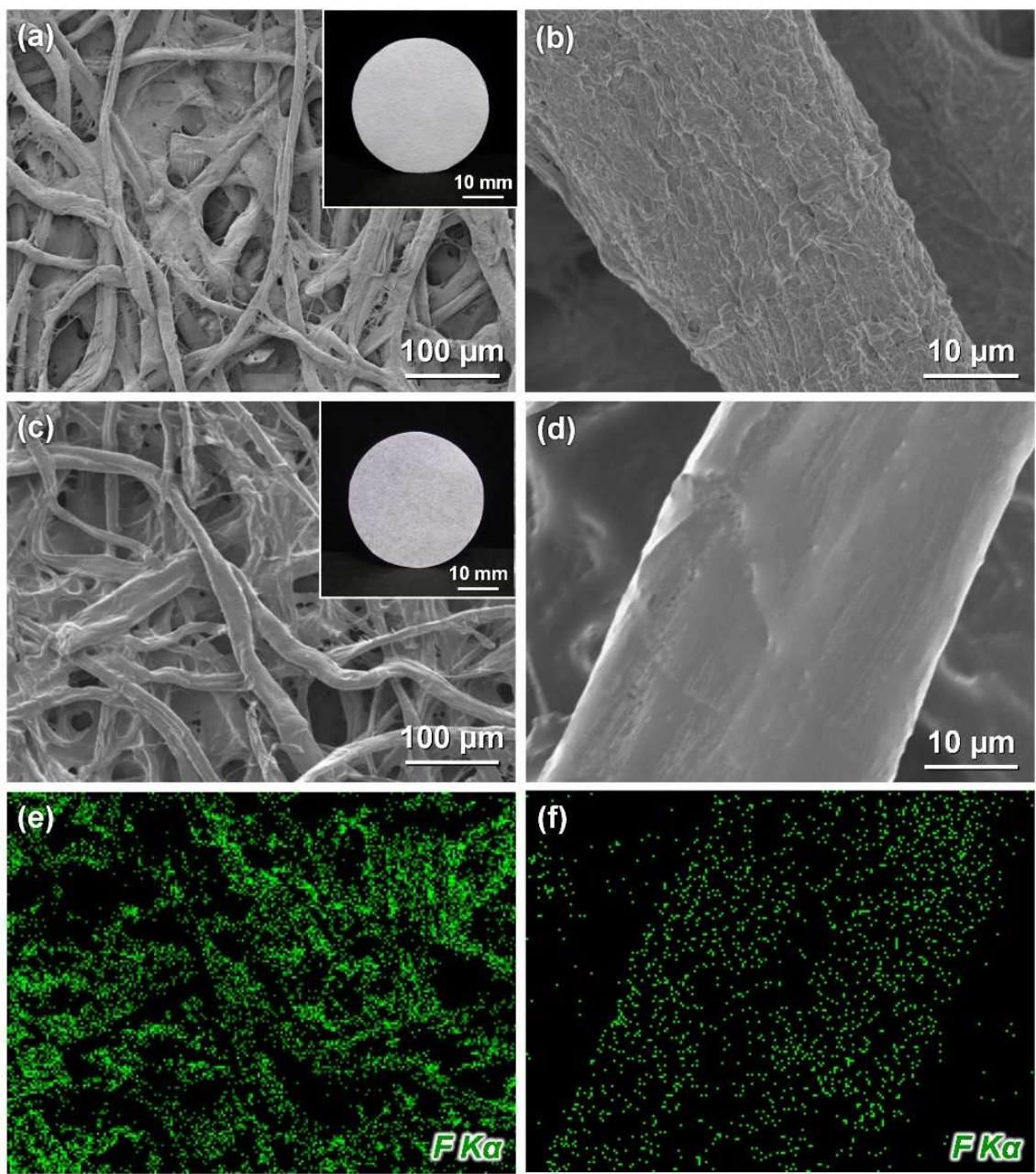

Figure 2. Cellulose filter paper before and after supporting of ionic liquid [bmim]NTf 2 . (a) Optical and FE-SEM images of original cellulose paper, and (b) FE-SEM image of cellulose pulp fiber within the paper. (c) Optical and FE-SEM images of cellulose paper after [bmim]NTf $\mathrm{N}_{2}$ treatment, (d) FE-SEM image of cellulose pulp fiber within the paper, and (e, f) EDX F element mapping images of (c) and (d), respectively. 

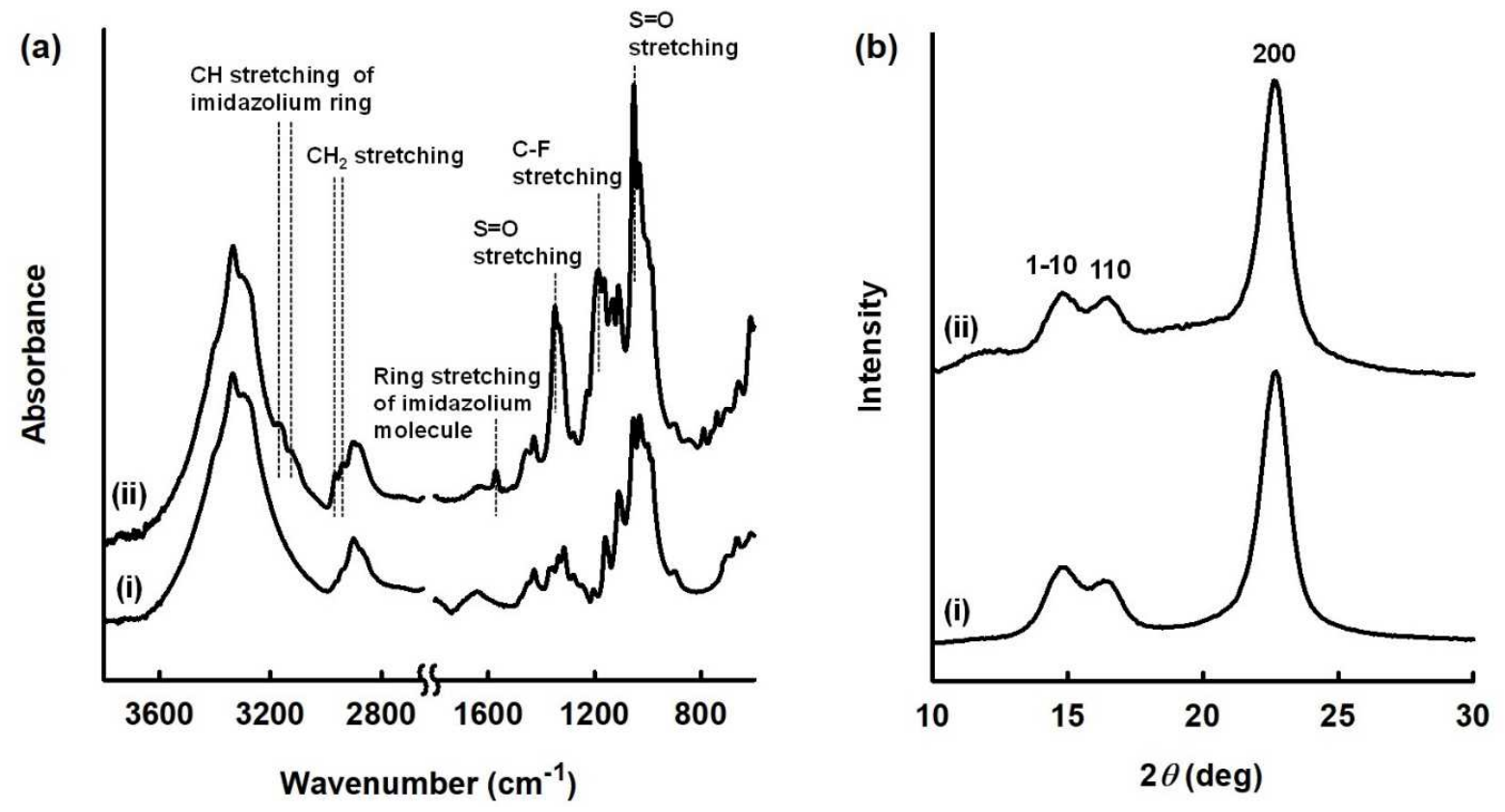

Figure 3. Characterization of cellulose filter paper before and after the supporting of [bmim]NTf .

(a) FT-IR/ATR spectra and (b) XRD patterns of cellulose paper (i) before and (ii) after [bmim]NTf 2 treatment. 
Table 1. Ionic liquid content, and electrical and physical properties of the original paper and [bmim]NTf $@$ paper

\begin{tabular}{lllll}
\hline & $\begin{array}{l}\text { Ionic liquid content } \\
\left(\text { mmol g-cellulose }^{-1}\right)\end{array}$ & $\begin{array}{l}\text { Volume resistivity } \\
(\Omega \cdot \mathrm{cm})\end{array}$ & $\begin{array}{l}\text { Young's modulus } \\
(\mathrm{GPa})\end{array}$ & $\begin{array}{l}\text { Tensile strength } \\
(\mathrm{MPa})\end{array}$ \\
\hline Original paper & - & $2.7 \times 10^{13}$ & $0.34 \pm 0.03$ & $5.49 \pm 0.36$ \\
{$[$ Bmim]NTf $@$ paper } & $2.25 \pm 0.06$ & $8.3 \times 10^{2}$ & $0.21 \pm 0.04$ & $2.88 \pm 0.39$ \\
\hline
\end{tabular}



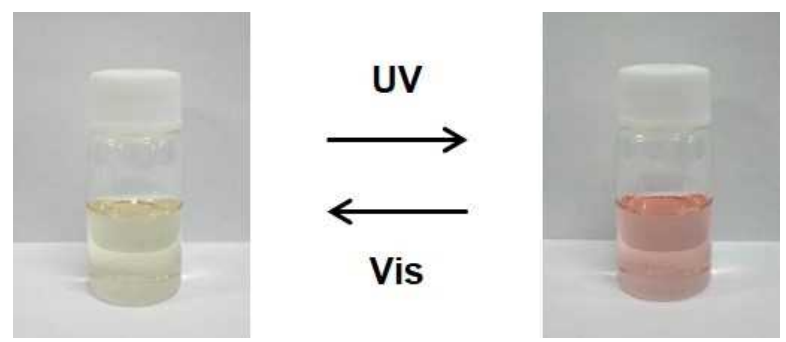

Figure 4. Optical images of the photochromic diarylethene 1,2-bis[2-methylbenzo[b]thiophen-3yl]-3,3,4,4,5,5-hexafluoro-1-cyclopentene/[bmim] $\mathrm{NTf}_{2}$ mixture after irradiation by UV and visible light. Diarylethene concentration: $50 \mu \mathrm{M}$. 

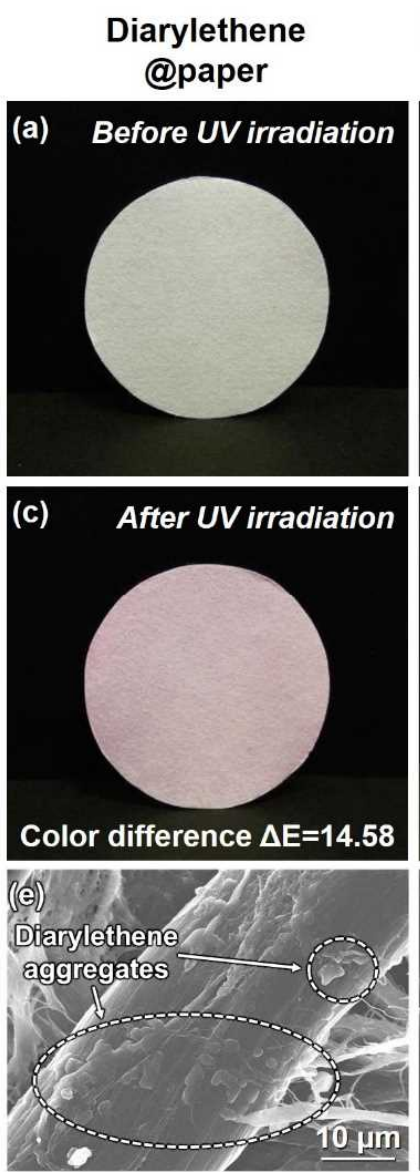

Diarylethene/[bmim] $\mathrm{NTf}_{2}$ @paper
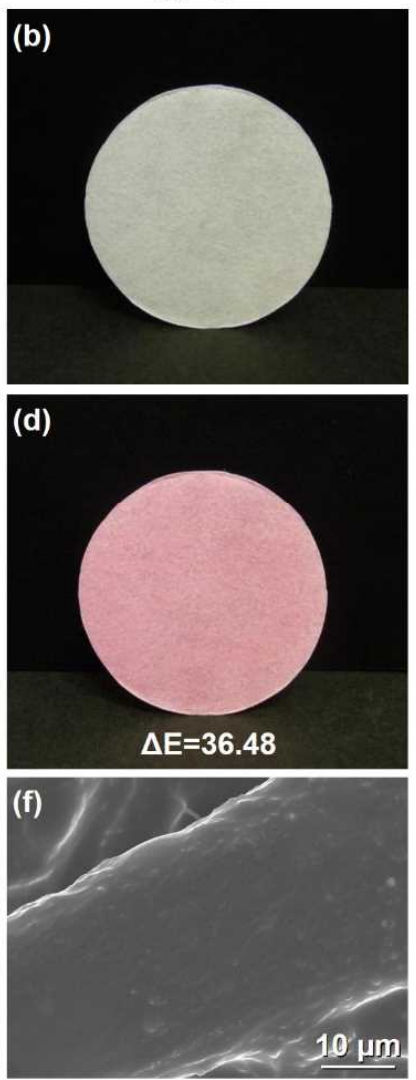
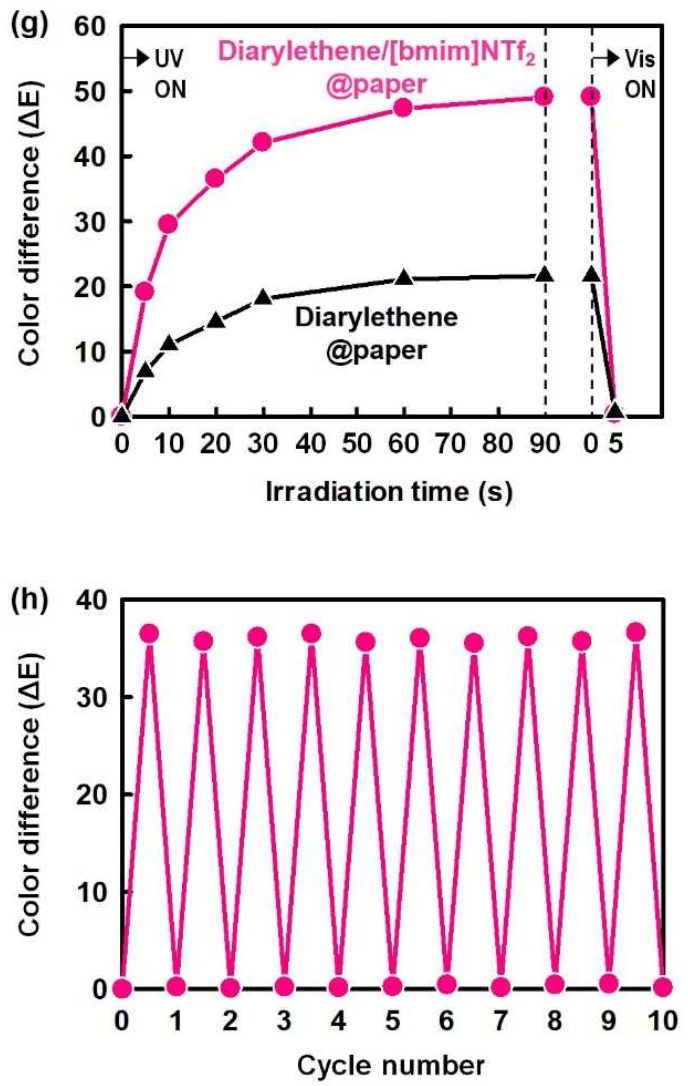

Figure 5. Photochromic performance of the diarylethene@paper with and without [bmim]NTf . $_{2}$

Optical images of the $(a, c)$ diarylethene@paper and $(b, d)$ diarylethene/[bmim]NTf $2 @$ paper $(a, b)$ before and (c, d) after UV irradiation for $20 \mathrm{~s}$. FE-SEM images of diarylethene on cellulose pulp fiber within the (e) original paper and (f) [bmim]NTf $f_{2} @$ paper. (g) Color difference values versus UV and visible light irradiation time for the diarylethene@paper and diarylethene/[bmim]NTf $f_{2}$ paper, and (h) change in color difference values for the diarylethene/[bmim]NTf $\mathrm{N}_{2} @$ paper upon alternate irradiation by UV (20 s) and visible light (5 s). Paper size: $33 \mathrm{~mm}$ in diameter. Diarylethene content: ca. $11 \mu \mathrm{mol}$. [Bmim]NTf 2 content: ca. 0.2 mmol. UV light: wavelength of $312 \mathrm{~nm}$, light intensity of $110 \mu \mathrm{W} \mathrm{cm}{ }^{-2}$. Visible light: neutral white lamp, light intensity of $100 \mu \mathrm{W} \mathrm{cm}{ }^{-2}$. 

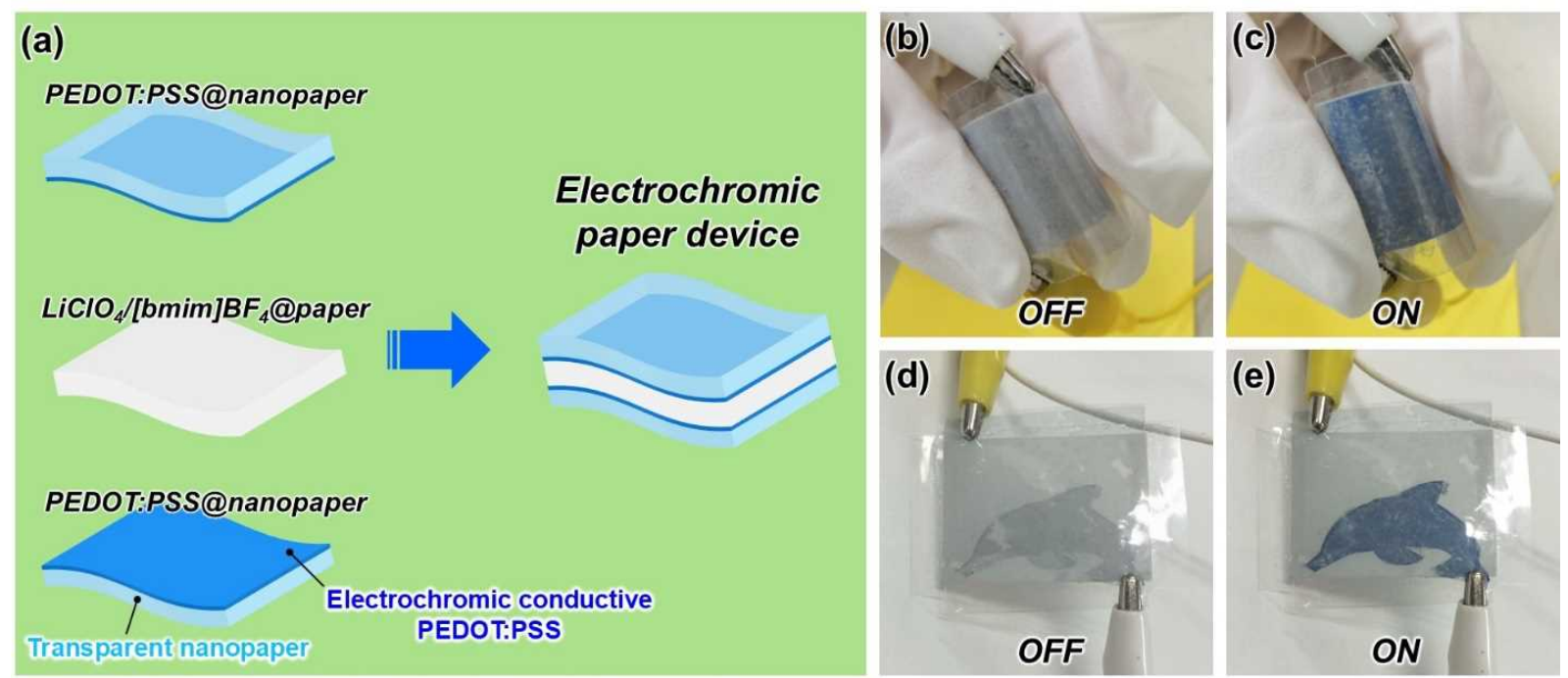

Figure 6. Electrochromic paper device. (a) Schematic illustration of the electrochromic paper device fabricated using two pieces of PEDOT:PSS@nanopaper and one piece of $\mathrm{LiClO}_{4} /[\mathrm{bmim}] \mathrm{BF} 4 @$ paper as transparent electrochromic electrodes and an electrolyte, respectively, (b, c) flexibility and corresponding performance of the electrochromic paper device, (d, e) dolphin-patterned electrochromism of the paper device. Operating voltage and current were $2.0 \mathrm{~V}$ and $0.06 \mathrm{~A}$, respectively. 


\section{Table of Contents Graphic}
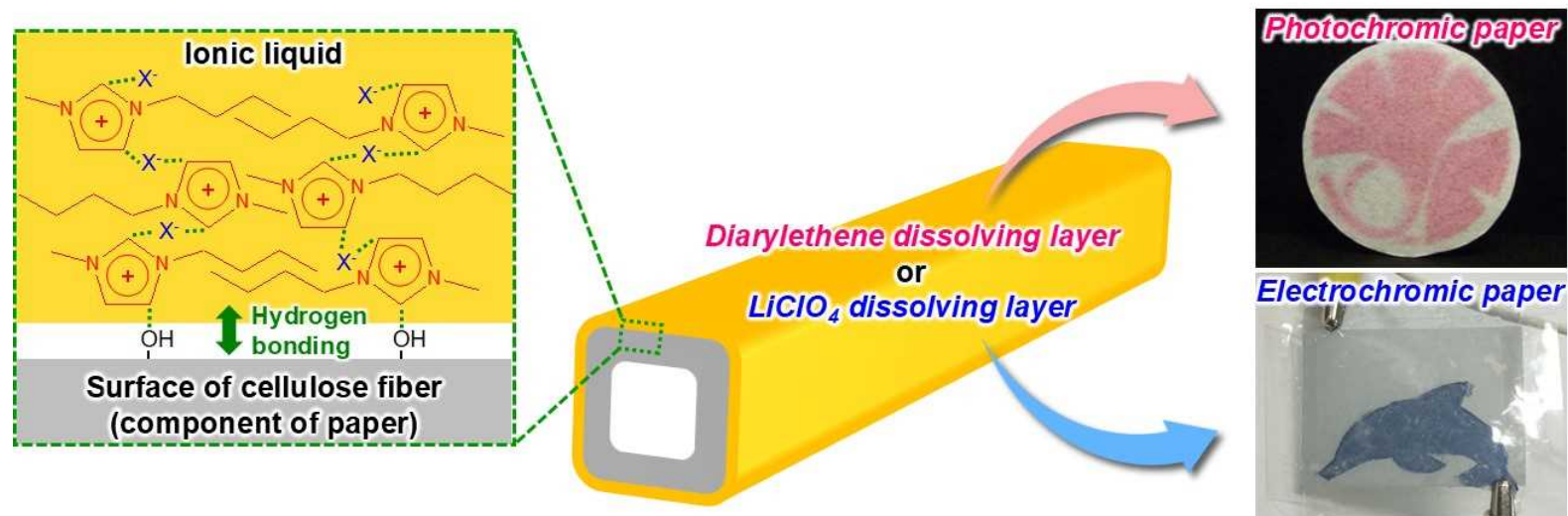

Electrochromic paper

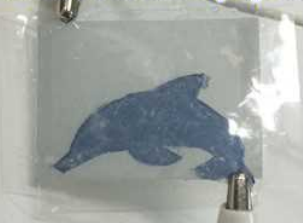




\title{
Supporting Information
}

\section{Ionic Liquid-Mediated Dispersion and Support of Functional \\ Molecules on Cellulose Fibers for Stimuli-Responsive Chromic}

\section{Paper Devices}

\author{
Hirotaka Koga, ${ }^{* \dagger}$ Masaya Nogi, ${ }^{\dagger}$ and Akira Isogai ${ }^{*}$
}

†The Institute of Scientific and Industrial Research, Osaka University, 8-1 Mihogaoka, Ibaraki, Osaka 567-0047, Japan

Department of Biomaterials Sciences, Graduate School of Agricultural and Life Sciences, The University of Tokyo, 1-1-1 Yayoi, Bunkyo-ku, Tokyo 113-8657, Japan

*Corresponding author: H. Koga

E-mail address: hkoga@eco.sanken.osaka-u.ac.jp 
(a)

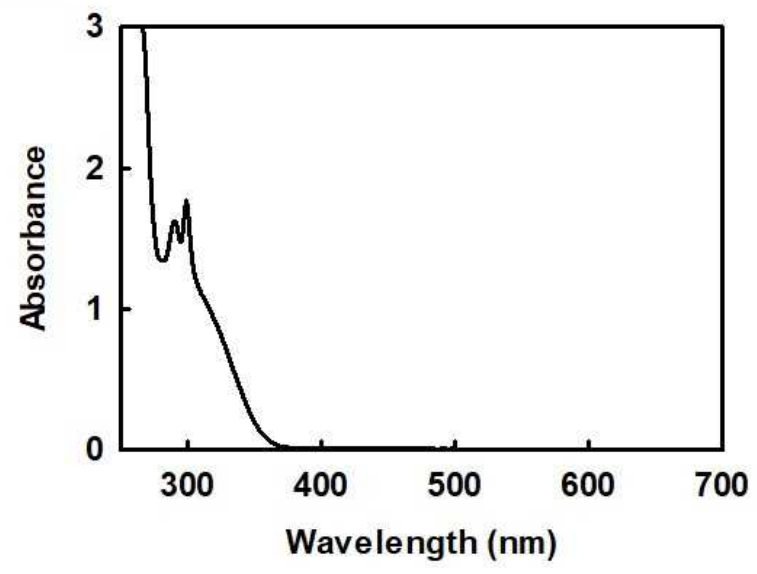

(b)

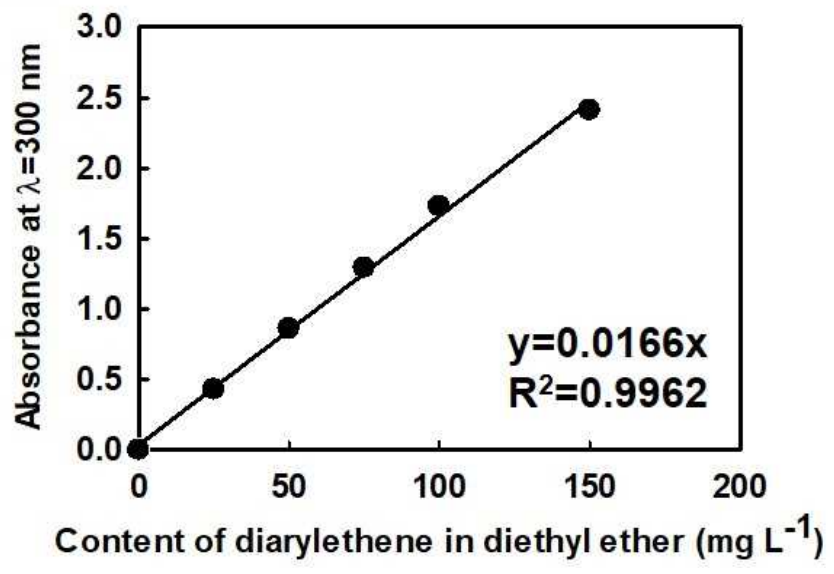

Figure S1. (a) UV-vis spectrum of diethyl ether solution of diarylethene, 1,2-bis[2methylbenzo[b]thiophen-3-yl]-3,3,4,4,5,5-hexafluoro-1-cyclopentene (100 $\mathrm{mg} \mathrm{L}^{-1}$ ), and (b) absorbance at a wavelength of $300 \mathrm{~nm}$ versus content of 1,2-bis[2-methylbenzo[b]thiophen-3-yl]3,3,4,4,5,5-hexafluoro-1-cyclopentene in diethyl ether.

As shown in Figure S1b, there was a proportional relationship $(\mathrm{y}=0.0166 \mathrm{x})$ with a high coefficient of determination $\left(\mathrm{R}^{2}=0.9962\right)$ between the absorbance at $300 \mathrm{~nm}(\mathrm{y})$ and content of diarylethene in diethyl ether (x). The diarylethene content in the paper was measured as follows. Residual diarylethene, which was not supported within the paper, was thoroughly dissolved in diethyl ether, and was then quantified by the absorbance at $300 \mathrm{~nm}$. The amount of diarylethene supported within the paper was estimated by subtraction. 

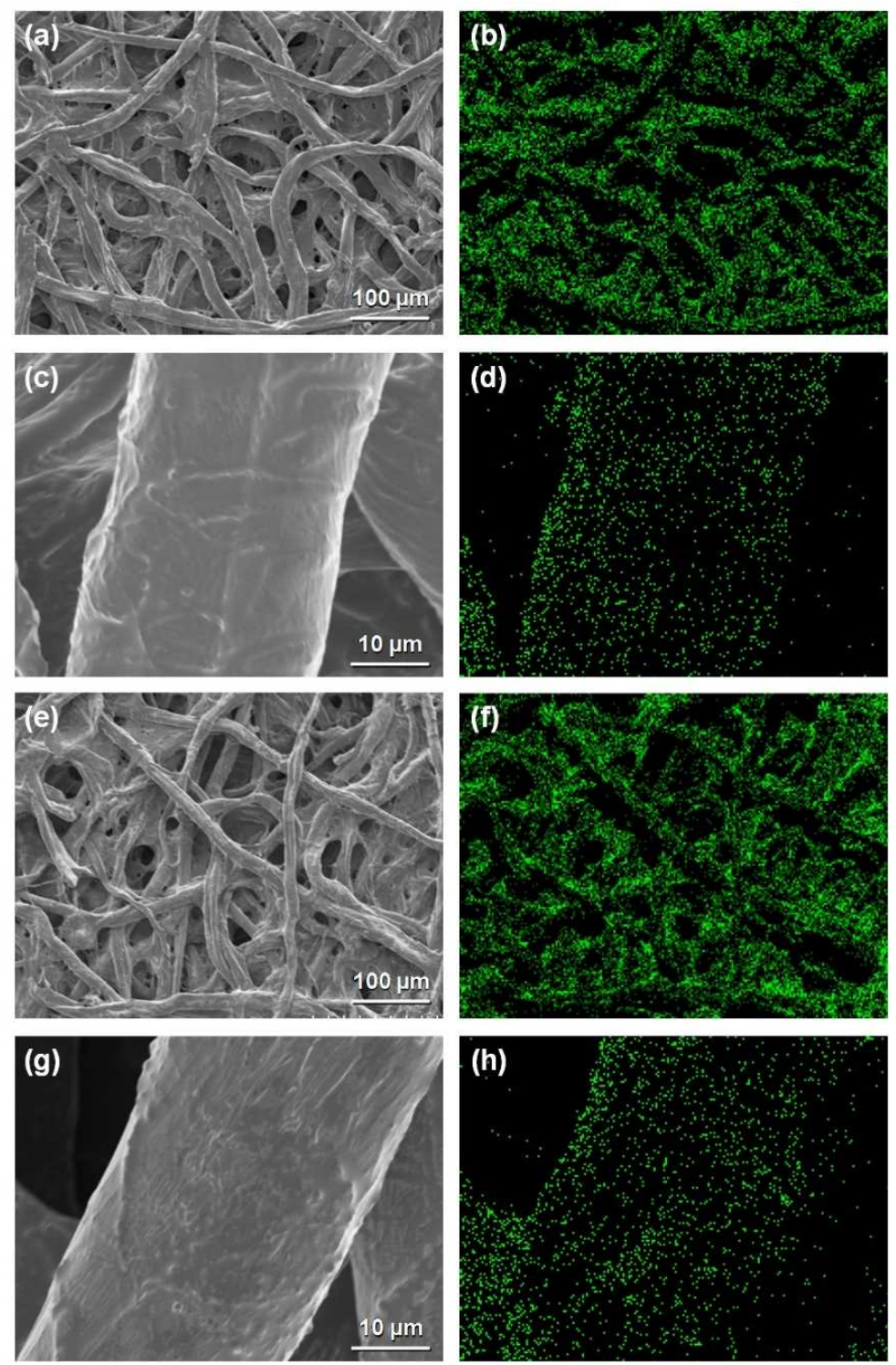

Figure S2. Cellulose filter paper before and after the supporting of $\left[\mathrm{bmim}^{\mathrm{B}}\right] \mathrm{BF}_{4}$ or $[\mathrm{bmim}] \mathrm{PF}_{6}$. (a, c) FE-SEM images and $(b, d)$ corresponding EDX $F$ element mapping images of the [bmim]BF4@paper. (e, g) FE-SEM images and (f, h) corresponding EDX F element mapping images of the [bmim] $\mathrm{PF}_{6} @$ paper.

As with $[\mathrm{bmim}] \mathrm{NTf}_{2}$ (Figure 2), $[\mathrm{bmim}] \mathrm{BF}_{4}$ and $[\mathrm{bmim}] \mathrm{PF}_{6}$ were also supported on the entire surface of the cellulose pulp fibers within the paper. 
(a)

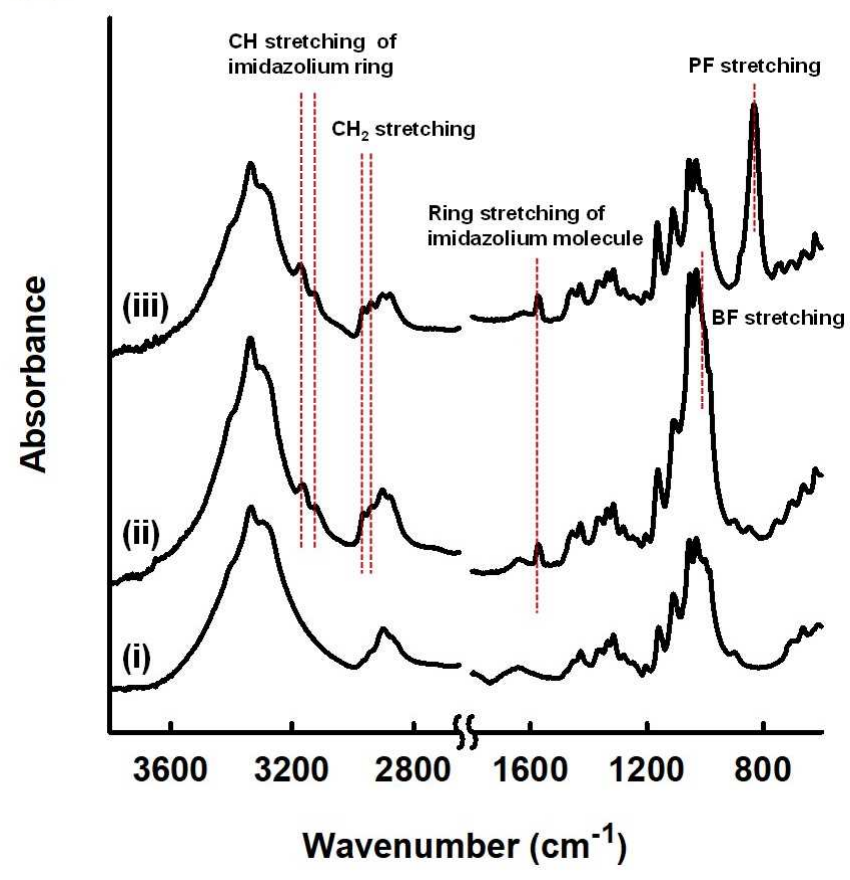

(b)

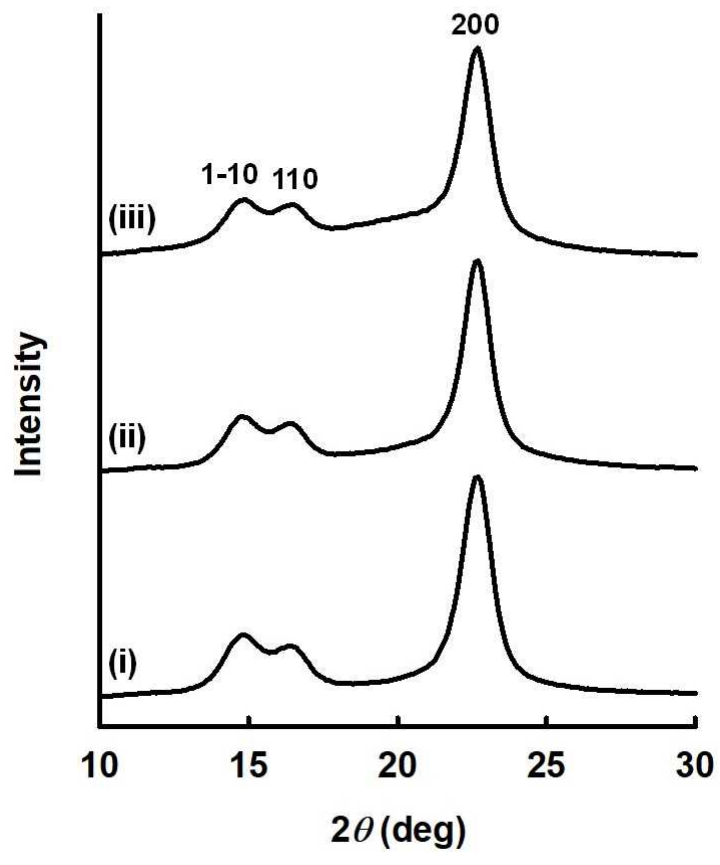

Figure S3. Characterization of cellulose filter paper before and after supporting of [bmim] $\mathrm{BF}_{4}$ or [bmim]PF6. (a) FT-IR/ATR spectra and (b) XRD patterns of cellulose paper (i) before and after treatment with (ii) $[\mathrm{bmim}] \mathrm{BF}_{4}$ and (iii) $\left[\mathrm{bmim}^{\mathrm{b}} \mathrm{PF}_{6}\right.$.

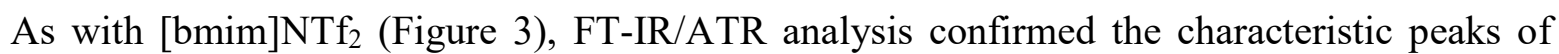
$[\mathrm{bmim}] \mathrm{BF}_{4}$ or $\left[\mathrm{bmim} \mathrm{PF}_{6}{ }^{1,2}\right.$ (Figure $\mathrm{S} 3 \mathrm{a}$ ), indicating the existence of $[\mathrm{bmim}] \mathrm{BF}_{4}$ or $[\mathrm{bmim}] \mathrm{PF}_{6}$ on the cellulose pulp fibers. As shown in Figure S3b, there was no significant change in the crystal structure of native cellulose (cellulose $\mathrm{I})^{3}$ even after treatment with $\left[\mathrm{bmim}^{-} \mathrm{BF}_{4}\right.$ or $[\mathrm{bmim}] \mathrm{PF}_{6}$. Then, the crystallinity index of cellulose I was slightly decreased from ca. $90 \%$ to $88 \%$ or $81 \%$ after treatment with $\left[\mathrm{bmim}^{\mathrm{B}}\right] \mathrm{BF}_{4}$ or $[\mathrm{bmim}] \mathrm{PF}_{6}$, respectively. These results suggested that $[\mathrm{bmim}] \mathrm{BF}_{4}$ or [bmim] $\mathrm{PF}_{6}$ were supported on the surfaces of cellulose fibers without large changes in the crystal structure of cellulose I. 
Table S1. Ionic liquid content, and electrical and physical properties of the [bmim] $\mathrm{BF}_{4} @$ paper and [bmim]PF6@paper

\begin{tabular}{lllll}
\hline & $\begin{array}{l}\text { Ionic liquid content } \\
\left(\mathrm{mmol} \text {-cellulose }{ }^{-1}\right)\end{array}$ & $\begin{array}{l}\text { Volume resistivity } \\
(\Omega \cdot c m)\end{array}$ & $\begin{array}{l}\text { Young's modulus } \\
(\mathrm{GPa})\end{array}$ & $\begin{array}{l}\text { Tensile strength } \\
(\mathrm{MPa})\end{array}$ \\
\hline$[\mathrm{Bmim}] \mathrm{BF}_{4} @$ paper & $2.39 \pm 0.09$ & $1.9 \times 10^{3}$ & $0.13 \pm 0.04$ & $2.39 \pm 0.49$ \\
{$[\mathrm{Bmim}] \mathrm{PF}_{6} @$ paper } & $2.17 \pm 0.08$ & $5.2 \times 10^{3}$ & $0.22 \pm 0.06$ & $3.02 \pm 0.22$ \\
\hline
\end{tabular}



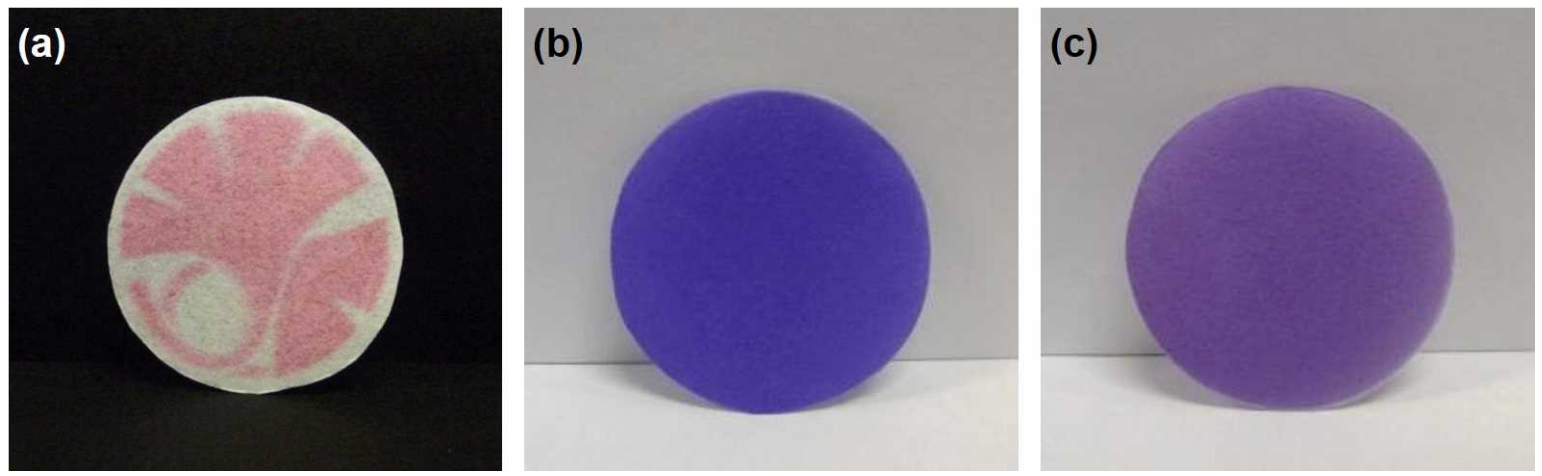

Figure S4. Photochromic paper display. (a) Photo-patterned pink coloration of the 1,2-bis[2methylbenzo[b]thiophen-3-yl]-3,3,4,4,5,5-hexafluoro-1-cyclopentene/[bmim] $\mathrm{NTf}_{2} @$ paper using black masking paper, (b) blue coloration of the 1,2-bis(2,4-dimethyl-5-phenyl-3-thienyl)3,3,4,4,5,5-hexafluoro-1-cyclopentene/[bmim]NTf $2 @$ paper, (c) purple coloration of the 1,2-bis[2methylbenzo[b]thiophen-3-yl]-3,3,4,4,5,5-hexafluoro-1-cyclopentene and 1,2-bis(2,4-dimethyl-5phenyl-3-thienyl)-3,3,4,4,5,5-hexafluoro-1-cyclopentene/[bmim]NTf $2 @$ paper. Paper size: 33 mm in diameter. Total diarylethene content: ca. $11 \mu \mathrm{mol}$. [Bmim] $\mathrm{NTf}_{2}$ content: ca. 0.2 mmol. UV light: wavelength of $312 \mathrm{~nm}$, light intensity of $110 \mu \mathrm{W} \mathrm{cm}{ }^{-2}$, irradiation time of $20 \mathrm{~s}$. 


\section{References}

1. Rajkumar, T.; Ranga Rao, G. Investigation of Hybrid Molecular Material Prepared by Ionic Liquid and Polyoxometalate Anion. J. Chem. Sci. 2008, 120, 587-594.

2. Seki, T.; Grunwaldt, J.-D.; Baiker, A. In Situ Attenuated Total Reflection Infrared Spectroscopy of Imidazolium-Based Room-Temperature Ionic Liquids under "Supercritical" $\mathrm{CO}_{2}$. J. Phys. Chem. B 2009, 113, 114-122.

3. Atalla, R. H.; Nagel, S. C. Cellulose: Its Regeneration in the Native Lattice. Science 1974, 185, $522-523$. 